This is a self-archived version of an original article. This version may differ from the original in pagination and typographic details.

Author(s): Rumfeldt, Jessica; Takala, Heikki; Liukkonen, Alli; Ihalainen, Janne

Title: UV-Vis Spectroscopy Reveals a Correlation Between Y263 and BV Protonation States in Bacteriophytochromes

Year: 2019

Version: Accepted version (Final draft)

Copyright: (C) 2019 American Society for Photobiology

Rights: In Copyright

Rights url: http://rightsstatements.org/page/InC/1.0/?language=en

Please cite the original version:

Rumfeldt, J., Takala, H., Liukkonen, A., \& Ihalainen, J. (2019). UV-Vis Spectroscopy Reveals a Correlation Between Y263 and BV Protonation States in Bacteriophytochromes. Photochemistry and Photobiology, 95(4), 969-979. https://doi.org/10.1111/php.13095 


\title{
UV-Vis Spectroscopy Reveals a Correlation Between Y263 and BV Protonation States in Bacteriophytochromes
}

\section{Supporting Information}

\author{
Jessica A. Rumfeldt ${ }^{1}$, Heikki Takala ${ }^{1,2}$, Alli Liukkonen ${ }^{1}$ and Janne A. Ihalainen, ${ }^{1, *}$ \\ ${ }^{1}$ University of Jyväskylä, Nanoscience Center, Department of Biological and Environmental \\ Science, Jyväskylä, Finland
}

${ }^{2}$ University of Helsinki, Faculty of Medicine, Anatomy, Helsinki, Finland

*Corresponding author e-mail: janne.ihalainen@jyu.fi (Janne A. Ihalainen) 


\section{SUPPORTING RESULTS AND DISCUSSION}
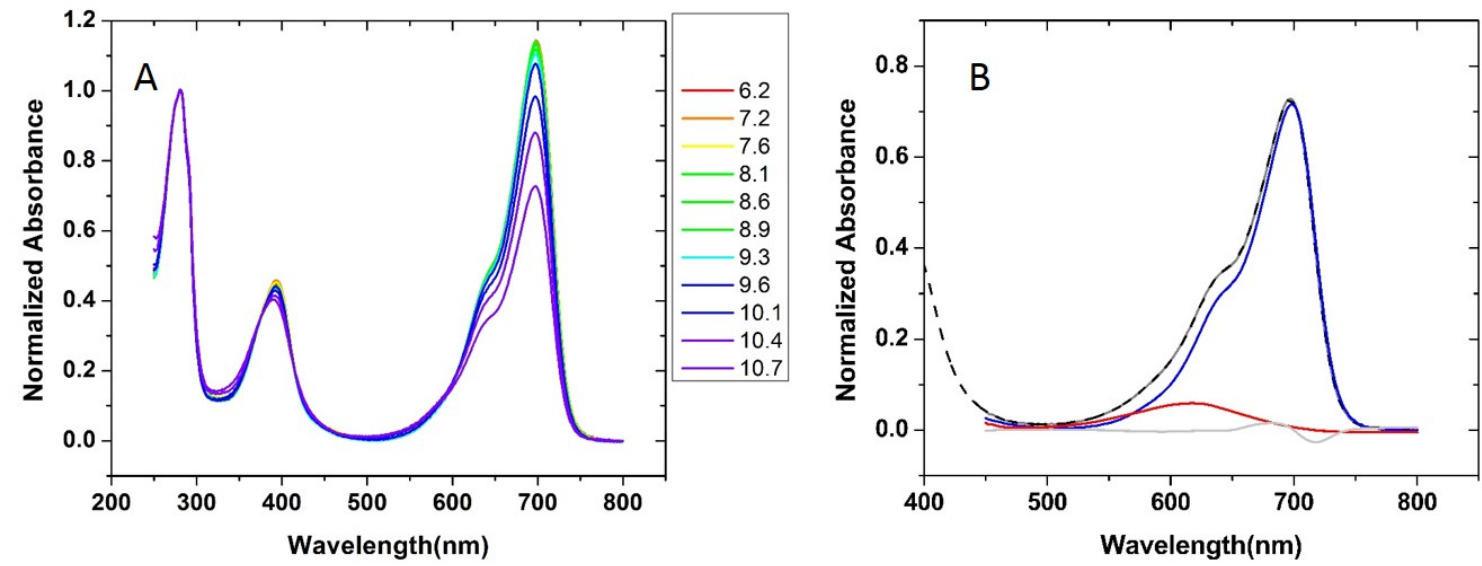

Figure S1: a) UV-Vis spectra as a function of $\mathrm{pH}$ for H290T b) Spectral decomposition. UV-Vis spectra of the Pr state at $\sim \mathrm{pH} 10.7$ (dashed lines) are shown decomposed into components. For H290T two major components Comp1 and Comp2 (blue and red solid lines respectively) and a minor component (light grey line) are needed to reconstruct the spectra between 450 and $800 \mathrm{~nm}$ (shown as dark grey solid line). 


\section{pH reversibility of absorbance}

The reversibility of BV absorbance upon decreasing the $\mathrm{pH}$ from $\mathrm{pH} 9.8$ to $\leq 7.1$ is $100 \%$.

For WT, when the initial $\mathrm{pH}$ is 10.4 the reversibility is $84 \%$ while for $\mathrm{Y} 263 \mathrm{~F}$ it is $95 \%$.

Thermodynamic analysis can therefore be performed on data obtained at $\mathrm{pH} 9.8$ and below with less reliable $\mathrm{p} K_{\mathrm{a}}$ values determined using data obtained above $\mathrm{pH} 9.8$. This only applies to $\mathrm{BV} \mathrm{p} K_{\mathrm{a}}$ values of WT, H290T and Y263F which we state in the main text as having $\mathrm{p} K_{\mathrm{a}}$ values above 10.
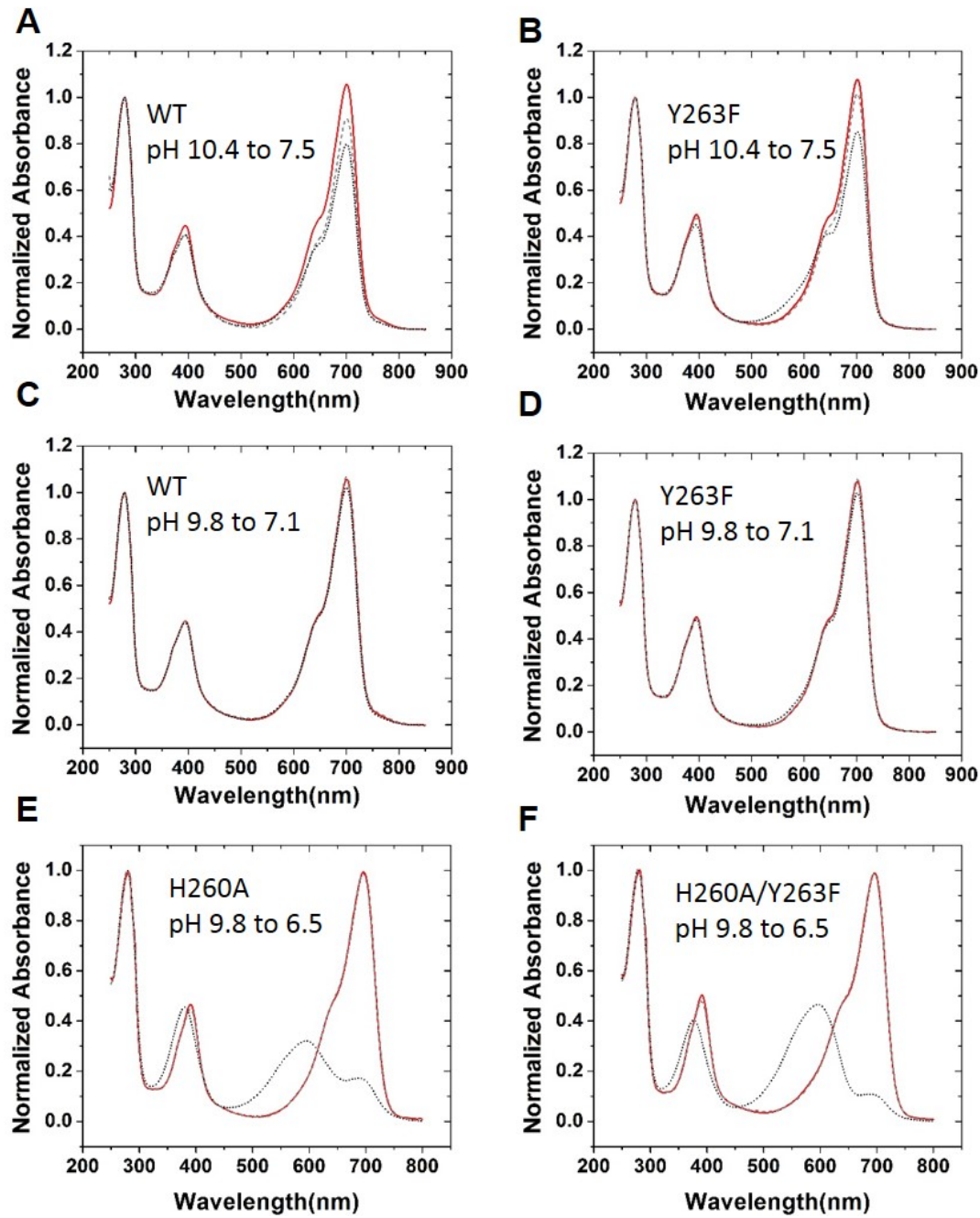

Figure S2. Reversibility of $\mathrm{BV}$ absorbance upon decreasing the $\mathrm{pH}$ from deprotonation to protonation conditions. The absorbance spectra of Dr-PSM when BV is protonated (red lines) is shown for A) WT and B) Y263F at $\mathrm{pH} 7.5$, C) WT and D) Y263F at pH 7.1, and E) H260A and F) $\mathrm{H} 260 \mathrm{~A} / \mathrm{Y} 263 \mathrm{~F}$ at $\mathrm{pH} 6.5$. These are compared with spectra (dashed grey lines) in which the 
specified construct was brought to the identical $\mathrm{pH}$ and protein concentration after an initial incubation in deprotonation conditions (10.4 or 9.8 as indicated on the graphs). Representative spectra of constructs in the deprotonated conditions are shown as dotted lines. Reversibility of the UV peak was $100 \%$ in all cases. Reversibility of the Q band for WT and Y263F from pH 10.4 to 7.5 was $84 \%$ and $95 \%$ respectively. Reversibility from 9.8 to $7.1(6.5)$ was $100 \%$ for WT, Y263F, $\mathrm{H} 260 \mathrm{~A}$ and $\mathrm{H} 260 \mathrm{~A} / \mathrm{Y} 263 \mathrm{~F}$.

\section{BV geometry}

There is no observable change in BV geometry due to $\mathrm{pH}$ as evidenced by absorbance of $\mathrm{Dr}$-PSM after urea denaturation. The BV chromophore maintains the original geometry adopted in the native state after urea-induced denaturation (1). This phenomenon can be used to determine the amount of BV isomerization (2). At all $\mathrm{pH}$ values up to 10.6 , there was no indication of $\mathrm{BV}$ isomerization indicating the increase in absorbance at $600 \mathrm{~nm}$ is not due to $\mathrm{pH}$-induced isomerization.
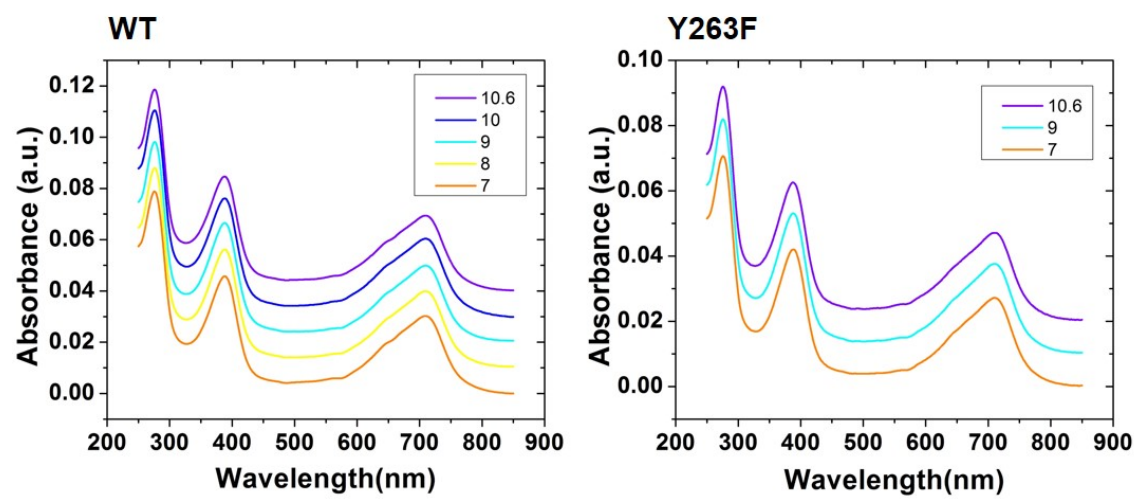

Figure S3. Maintenance of the $\operatorname{Pr}^{\mathrm{ZZZ}}$ conformation of $\mathrm{BV}$ in high $\mathrm{pH}$ as indicated by Urea denaturation. Protein in $\mathrm{pH}$ buffered solutions ( $\mathrm{pH}$ indicated on the graphs) was diluted into $10 \mathrm{M}$ Urea $\mathrm{pH} 2.5$ to obtain a final concentration of $8 \mathrm{M}$ Urea. 


\section{Observation of Non-two-state behaviour in pH titration curves}
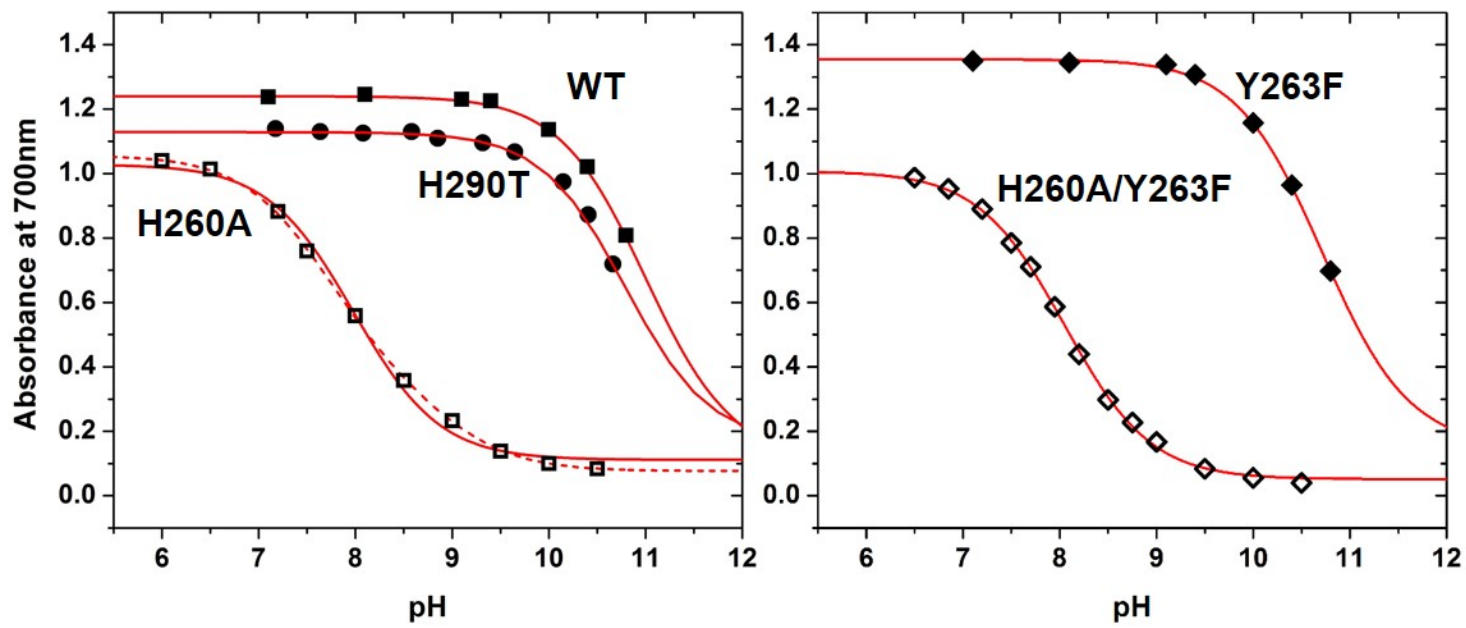

Figure S4: Plot of absorption at $700 \mathrm{~nm}$ as a function of $\mathrm{pH}$ for WT (solid squares), H290T (solid circles), H260A (open squares), Y263F (solid diamonds), H260A/Y263F (open diamonds). Solid red lines represent fits to a model with one $\mathrm{p} K_{\mathrm{a}}$ while the dashed red line for H260A is a fit to the model with two $\mathrm{p} K_{\mathrm{a}} \mathrm{s}$.

A
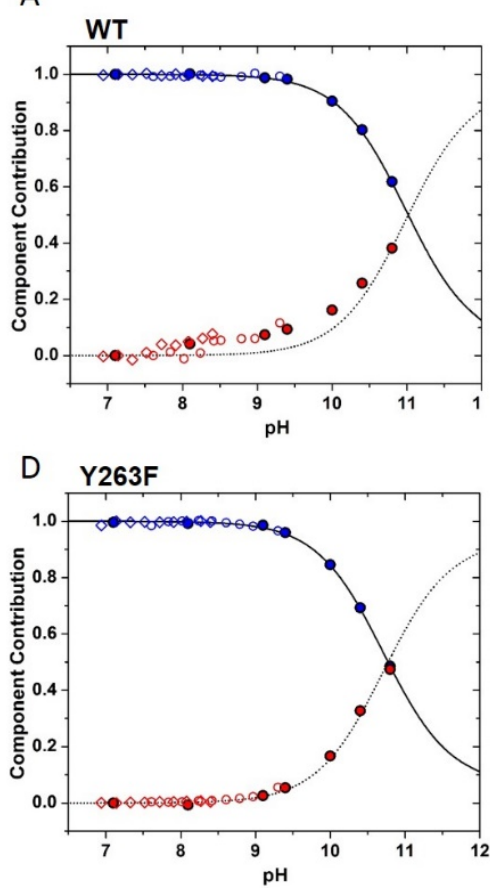

B

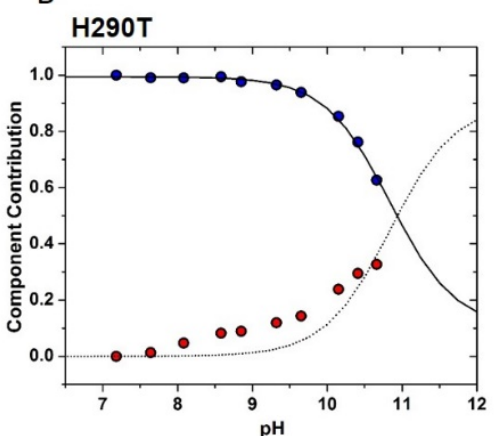

E H260A/Y263F

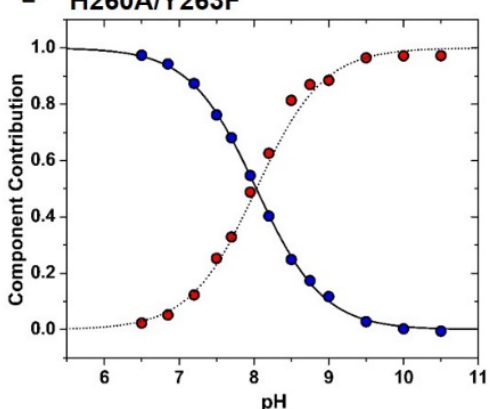

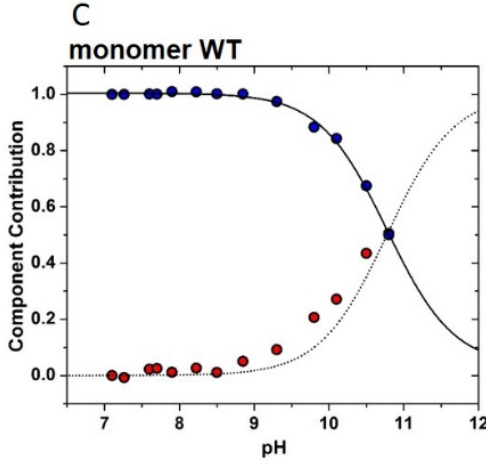

Figure S5. Deviation observed from a fit to one $\mathrm{p} K_{\mathrm{a}}$ for a) WT b) H290T and c) monomer WT but not for d) Y263F or e) H260A/Y263F. The contribution of Comp1 shown as closed blue circles and Comp2 as closed red circles. The solid line is the single fit to one $\mathrm{p} K_{\mathrm{a}}$ and the dotted line is its 
reciprocal. For constructs with the Y263F mutation, the Comp1 and Comp2 component fractions as a function of $\mathrm{pH}$ are mirror images of each other with identical $\mathrm{p} K_{\mathrm{a}}$ values. For WT and $\mathrm{Y} 263 \mathrm{~F}$, the $\mathrm{pH}$ titration was also performed with Hepes $(\diamond)$ and Bicine $(\bigcirc)$ buffer in the $\mathrm{pH}$ range 7 to 9.3 which shows that this trend is not buffer dependent.

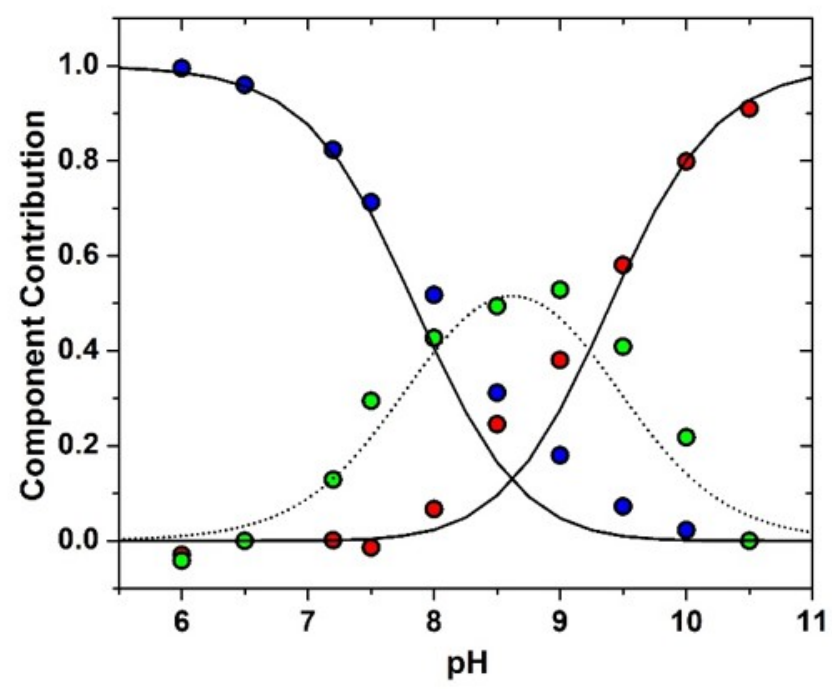

Figure S6. Global fitting of the major spectral components of H260A to the sequential 3-state model. There is deviation from the fit between $\mathrm{pH} 7.5$ and 9.5. Symbols as in the main text Figure 4.

\section{Direct evidence for Y263-OH deprotonation - absorbance and fluorescence in the UV region}

In order to obtain direct evidence for $\mathrm{Y} 263-\mathrm{OH}$ deprotonation, the absorbance in the UV region was closely observed and analyzed (Figure S7 and S8, and Supporting Methods). The protonated and deprotonated absorbance spectra of free L-tyrosine in Figure S7(F) is similar to what has been observed previously for $N$-Acetyl-L-tyrosinamide (NATyrA) (3). The tyrosine difference spectra has a peak at $293 \mathrm{~nm}$ and a trough at $273 \mathrm{~nm}$ which is also observed in the difference spectra for all constructs at $\mathrm{pH}$ values of 10 or greater and most likely reflects deprotonation of one or more of the solvent exposed tyrosines which would have a $\mathrm{p} K_{\mathrm{a}}$ value near 10.5 (4). The isosbestic points 
observed in Figure S7 at $280 \mathrm{~nm}$ are artifacts of the normalization method. The deprotonation of NATyrA has isosbestic points at 269 and $278 \mathrm{~nm}(3)$.

For constructs with Y263, the difference spectra at low $\mathrm{pH}(\mathrm{pH} 7$ to 9) has a different appearance than those at higher $\mathrm{pH}$ values, with a peak centered at $301 \mathrm{~nm}$ and a small trough at $286 \mathrm{~nm}$.(Figure S7B,C,E) For constructs with the Y263F mutation, the difference spectra at the same $\mathrm{pH}$ values (pH 7 to 9) do not show the same peak at $301 \mathrm{~nm}$.(Figure S7A,D) Together, this is interpreted as evidence for $\mathrm{Y} 263-\mathrm{OH}$ deprotonation with influence of $\mathrm{BV}$ and binding site amino acid side-chains altering the absorption properties of the tyrosinate.

The $\Delta$ Absorbance at specific wavelengths are plotted as a function of $\mathrm{pH}$ in Figure $\mathrm{S} 8$ along with the fraction of Y263-0- $\{([\mathrm{BA}]+[\mathrm{BB}]) /([\mathrm{AA}]+[\mathrm{AB}]+[\mathrm{BA}]+[\mathrm{BB}])\}$ calculated assuming the four-state model in Figure 5 and the $\mathrm{p} K_{\mathrm{a}}$ values in Table 2. In A) Y263F, WT and H290T and B) $\mathrm{H} 260 \mathrm{~A} / \mathrm{Y} 263 \mathrm{~F}$ and $\mathrm{H} 260 \mathrm{~A}$ are plotted the $\Delta$ Absorbance averaged for $300-302 \mathrm{~nm}$. The constructs with Y263 (red symbols) show a larger $\Delta$ Absorbance in the $\mathrm{pH}$ range between 7 and 10 than those with the Y263F mutation (black symbols) indicating that Y263 is deprotonating. In panels C) Y263F, WT and H290T and D) H260A/Y263F and H260A the $\Delta$ Absorbance at $293 \mathrm{~nm}$ shows relatively little change until $\mathrm{pH} 10$ for all but H260A which shows a small gradual increase in this region. As observed in the difference spectra, this is consistent with an initial deprotonation of Y263-OH between $\mathrm{pH} 7$ and 10 with subsequent deprotonation of solvent exposed tyrosines after $\mathrm{pH} 10$. The theoretical absorbance at $300-302 \mathrm{~nm}$ and $293 \mathrm{~nm}$ at $\mathrm{pH} 9$ can be calculated using tyrosine difference spectra in Figure S7(F) and Figure S8(E). Using these values, data from WT, H290T and H260A are not completely consistent with one tyrosine deprotonation per monomer below $\mathrm{pH} 10$ which may be due to influence of nearby charges as discussed above. 
Since deprotonation of tyrosine results in an increased fluorescence at $340 \mathrm{~nm},(5)$ fluorescence measurements were also carried out to provide additional direct evidence for Y263$\mathrm{OH}$ deprotonation.(Figure 8) The emission spectra (excitation at $275 \mathrm{~nm}$ ) are plotted in Figure S9A for WT and Y263F and S9B for H260A and H260A/Y263F. Note that the concentration of WT and $\mathrm{Y} 263 \mathrm{~F}$ is $\sim 4 \mu \mathrm{M}$ and the concentration of $\mathrm{H} 260 \mathrm{~A}$ and $\mathrm{H} 260 \mathrm{~A} / \mathrm{Y} 263 \mathrm{~F}$ is $\sim 2.2 \mu \mathrm{M}$. Except for Y263F, fluorescence intensity is greater at $\mathrm{pH} 8.9$ (dashed lines) than at $\mathrm{pH} 7.1$ (solid lines). The difference spectra ( $\mathrm{pH} 8.9$ minus $\mathrm{pH}$ 7.1) are shown in C) for WT and Y263F and D) H260A and H260A/Y263F. From this it can be seen that the pH-induced fluorescence increase is larger for WT and H260A constructs than for their corresponding tyrosine mutations, Y263F and $\mathrm{H} 260 \mathrm{~A} / \mathrm{Y} 263 \mathrm{~F}$. The $\Delta \Delta$ Fluorescence spectra are plotted in S9 E) $\Delta \mathrm{WT}$ minus $\Delta \mathrm{Y} 263 \mathrm{~F}$ and F) $\Delta \mathrm{H} 260 \mathrm{~A}$ minus $\Delta \mathrm{H} 260 \mathrm{~A} / \mathrm{Y} 263 \mathrm{~F}$. Using Figure $\mathrm{S} 8(\mathrm{E})$ the increase in the fractional population of Y263-O- from $\mathrm{pH} 7.1$ to 8.9 is 0.72 for $\mathrm{WT}$ and 0.25 for H260A. From this and the difference in protein concentration, it is expected that the $\Delta \Delta$ Fluorescence of WT should be $\sim 5$ times higher than for H260A which is similar to what is observed. Therefore, both UV-absorbance and fluorescence are consistent with Y263-OH deprotonation. 
A

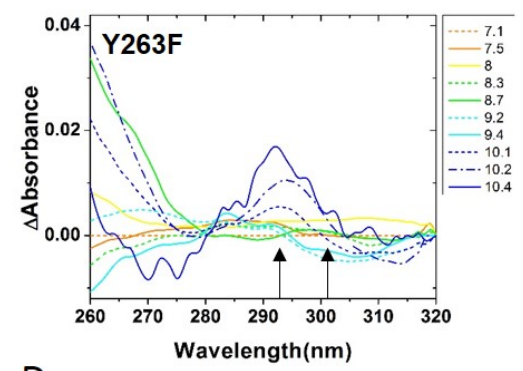

D

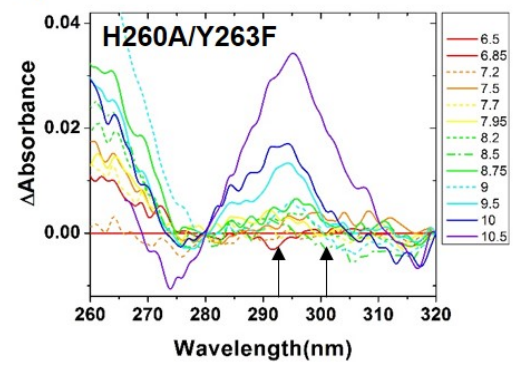

B

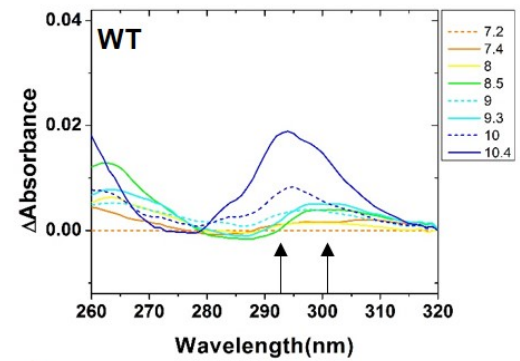

$E$

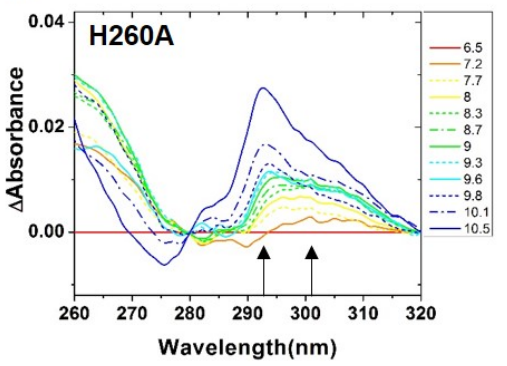

C
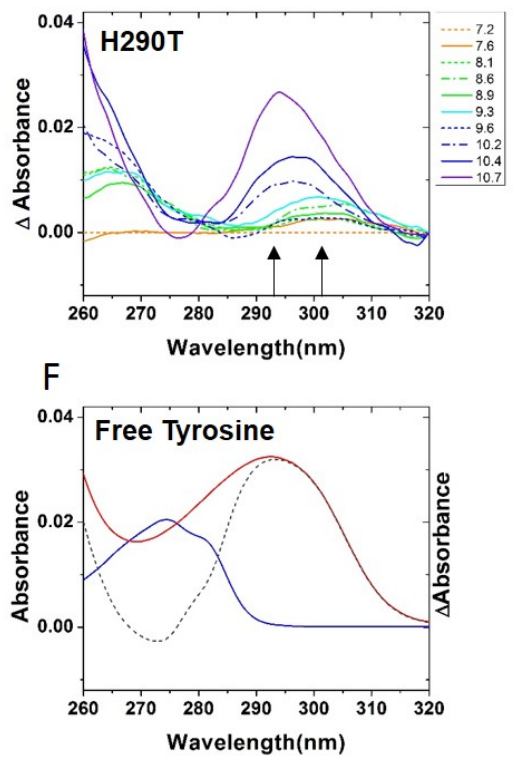

Figure S7. Changes in UV-absorption as a function of $\mathrm{pH}$. For a given construct, the UV region of the absorption spectra $(250-320 \mathrm{~nm})$ was normalized as outlined in supporting methods. The spectrum measured at the lowest $\mathrm{pH}$ (6.5 to 7.2) was then subtracted from the spectra measured at the higher $\mathrm{pH}$ values ( $\mathrm{pH}$ values indicated beside the graphs). The resulting difference spectra are shown in A) for Y263F, B) WT C) H290T D) H260A/Y263F and E) H260A. Traces have been smoothed for clarity. For comparison, the spectra of free L-tyrosine in solution is shown in F) fully protonated (blue), deprotonated (red) as well as the difference spectra, deprotonated minus protonated (dashed grey line). The absorbance of these traces have been scaled to correspond to one tyrosine per monomer of Dr-PSM (see Supporting Information Methods). 
A
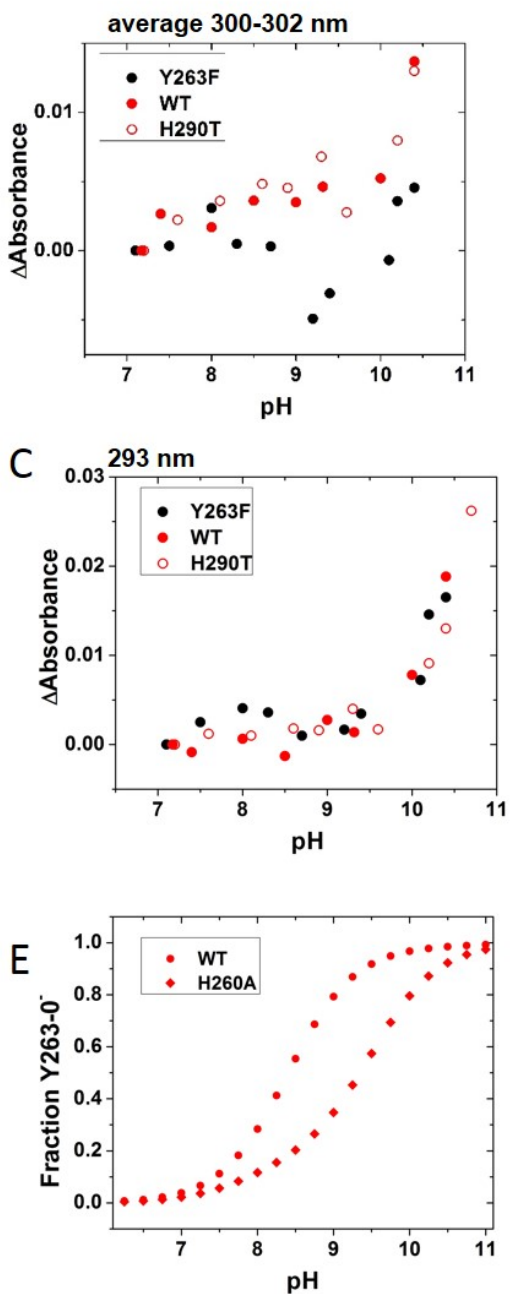

B
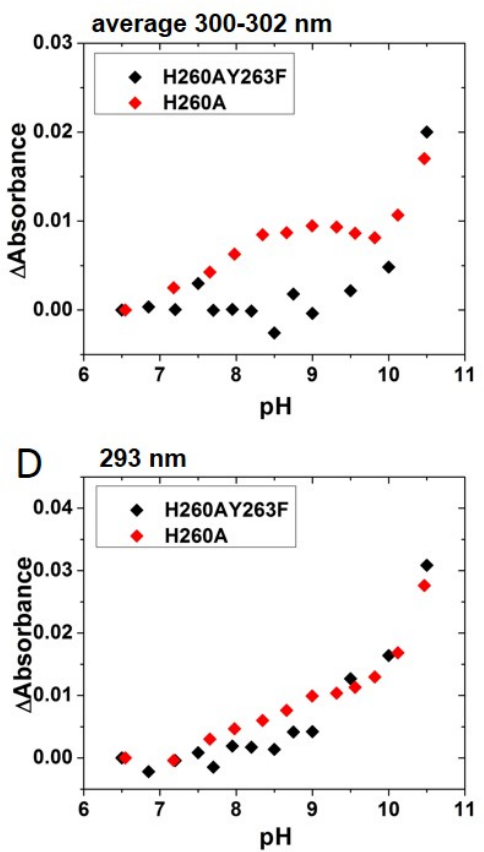

Figure S8. Plots of the absorption difference at the specific wavelength regions indicated by arrows in Figure S7. The absorbance difference averaged for wavelengths 300 to $302 \mathrm{~nm}$ is plotted in A) for Y263F, WT and H290T and in B) for H260A/Y263F and H260A. The absorption difference in this region for constructs with Y263: WT, H290T, H260A (red symbols), shows an increase relative to $\mathrm{Y} 263 \mathrm{~F}$ and $\mathrm{H} 263 \mathrm{~A} / \mathrm{Y} 263 \mathrm{~F}$ (black symbols) starting after $\mathrm{pH} 7$. The absorbance difference at $293 \mathrm{~nm}$ as a function of $\mathrm{pH}$ is shown in C) for Y263F, WT and H290T and in D) for H260A/Y263F and $\mathrm{H} 260 \mathrm{~A}$. In E, the fraction of Y263-O- as a function of $\mathrm{pH}$ is shown for WT (circles) and $\mathrm{H} 260 \mathrm{~A}$ (diamonds) which has been calculated using the model in Figure 5 in the main text (i.e. species $\mathrm{BA}+\mathrm{BB})$ and the corresponding $\mathrm{p} K_{\mathrm{a}}$ values in Table 2 main text. 
A
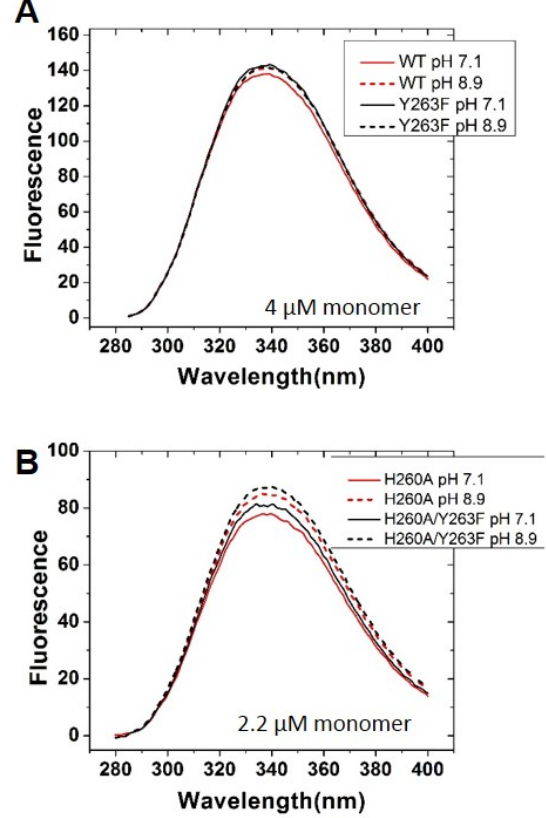

C

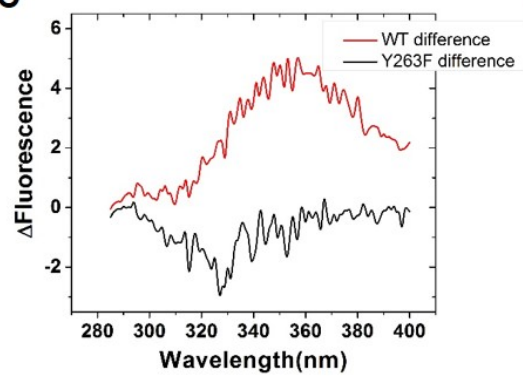

E
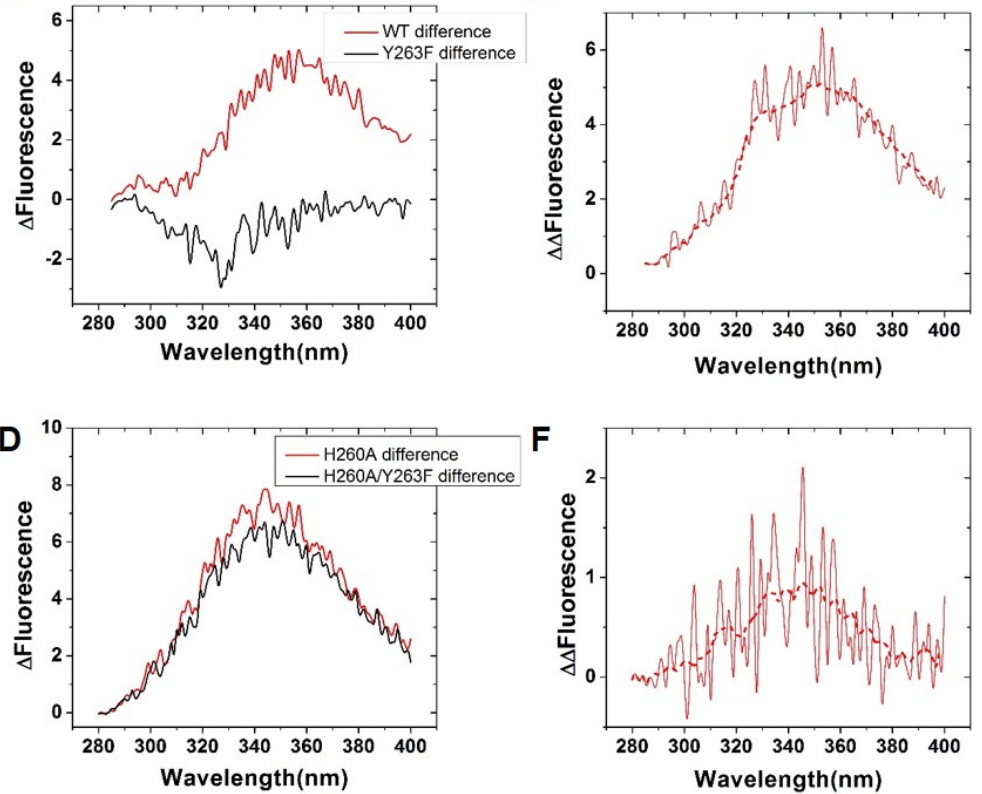

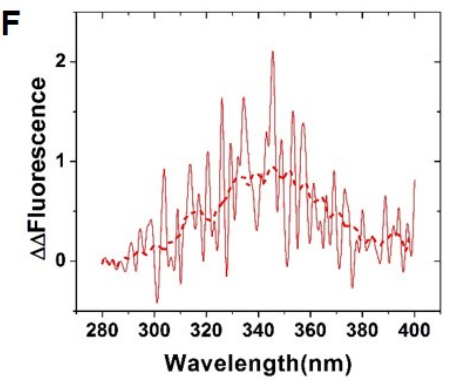

Figure S9. UV Fluorescence at $\mathrm{pH} 7.1$ (solid lines) and $\mathrm{pH} 8.9$ (dashed lines) of A) WT (red lines) and Y263F (black lines) and B) H260A (red lines) and H260A/Y263F (black lines). The difference spectra (pH 8.9 minus $\mathrm{pH} 7.1$ ) is shown in C) for WT (red) and Y263F (black) and D) for H260A (red) and H260A/Y263F (black). The double difference spectra are shown for WT in E) (WT difference minus Y263F difference) and for H260A (H260A difference minus H260A/Y263F difference) in $\mathrm{F}$. The sold lines are raw $\Delta \Delta$ Fluorescence and the dashed lines represent the smoothed data.

\section{Error Estimation}
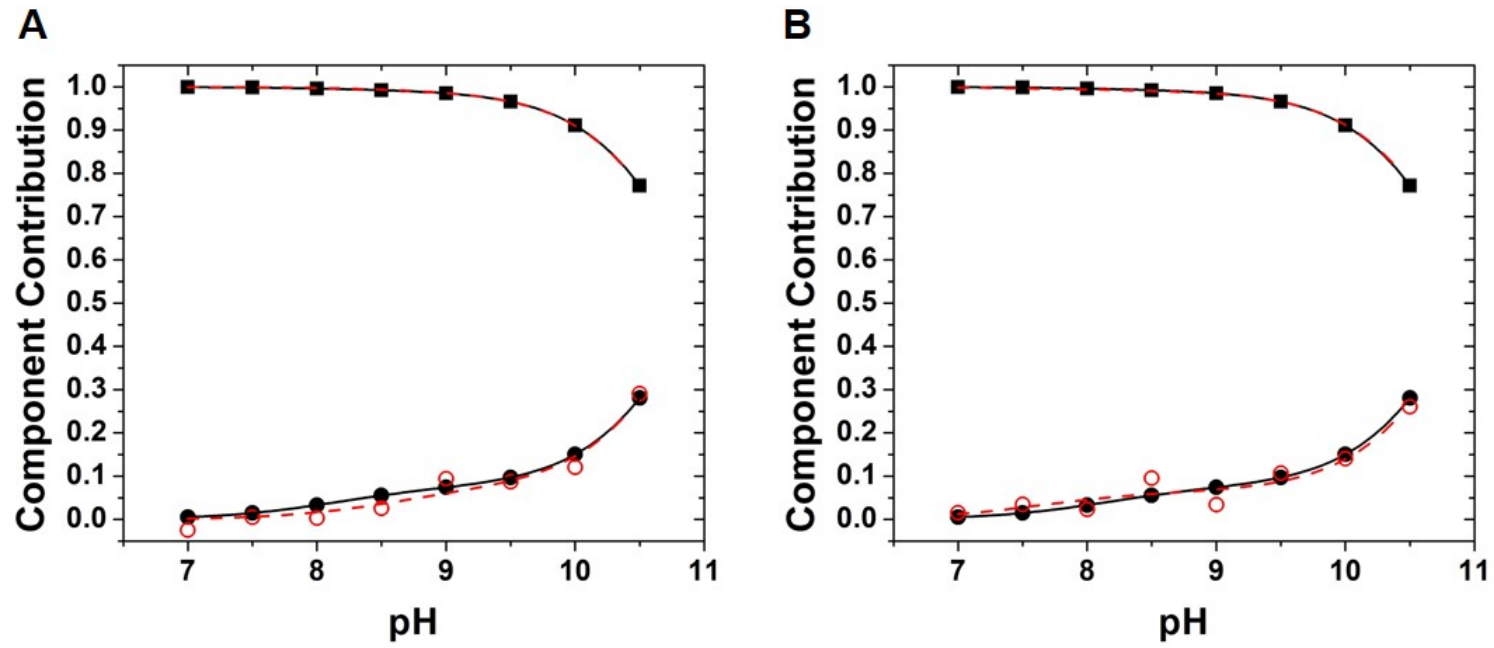

Figure S10. Error estimation. Data was generated using the four $\mathrm{p} K_{\mathrm{a}}$ model (Equation 1 ) and $\mathrm{p} K_{\mathrm{a}} 1$ 2, 3 and 4 values of 10.2, 11.0,8.1 and 8.9 respectively (black symbols). Using this ideal data, the fitted values converged to the same $\mathrm{p} K_{\mathrm{a}}$ values used to generate the data (solid black lines). Noise 
was then added to Comp2 (red symbols) using a random number generator. Specifically, integer values from -3 to +3 or -4 to +4 were generated for each data point which indicated the addition of -0.03 to 0.03 (A) or -0.04 to 0.04 (B) respectively. In A) the fitted $\mathrm{p} K_{\mathrm{a}} 1,2,3$ and 4 values are $10.5,11.0,8.6$ and 9.1 respectively. In $\mathrm{B}$ ) the fitted $\mathrm{p} K_{\mathrm{a}} 1,2,3$ and 4 values are 9.7, 11.1, 7.6 and 8.9 respectively. From this is appears that noise in the data has a larger contribution to errors in $\mathrm{p} K_{\mathrm{a}}$ than the inability to include data beyond $\mathrm{pH} 10.5$. This error is estimated to be $\pm 0.5 \mathrm{pH}$ units.

Tables

Table S1. Wavelength maxima determined from UV-Vis spectra of Dr-PSM variants in Pr

\begin{tabular}{|c|c|c|c|c|}
\hline \multirow[b]{3}{*}{ CBD-PHY } & \multicolumn{4}{|c|}{ Dark PrZZZ } \\
\hline & \multicolumn{2}{|c|}{ Low pH } & \multicolumn{2}{|c|}{ High pH } \\
\hline & Soret & Q & Soret & Q \\
\hline WT & 395 & 701 & 391 & 631 \\
\hline Y263F & 396 & 702 & 391 & 616 \\
\hline H290T & 393 & 698 & 391 & 620 \\
\hline $\mathrm{H} 260 \mathrm{~A}$ & 390 & 696 & 381 & 600 \\
\hline $\mathrm{H} 260 \mathrm{~A} / \mathrm{Y} 263 \mathrm{~F}$ & 391 & 696 & 377 & 598 \\
\hline
\end{tabular}

Table S2. Parameters determined from fitting spectral components to models involving one to two $\mathrm{p} K_{\mathrm{a}}$ values.

\begin{tabular}{llccc}
\hline Protein & & & BV & Y263-OH \\
\hline$D r-P S M$ & Data Set $^{\mathrm{a}}$ & Fit $^{\mathrm{b}}$ & $\mathrm{p} K_{\mathrm{a} 1}$ & $\mathrm{p} K_{\mathrm{a} 3}$ \\
\hline $\mathrm{WT}^{\mathrm{c}}$ & $\mathrm{C} 1$ & $\mathrm{~S}-1 \mathrm{p} K_{\mathrm{a}}$ & 10.9 & - \\
& $\mathrm{C} 1$ \& C2 & $\mathrm{G}-2 \mathrm{p} K_{\mathrm{a}}$ & 10.9 & 8.4 \\
H290T $^{\mathrm{c}}$ & $\mathrm{C} 1$ & $\mathrm{~S}-1 \mathrm{p} K_{\mathrm{a}}$ & $10.6^{*}$ & - \\
& $\mathrm{C} 1 \& \mathrm{C} 2$ & $\mathrm{G}-2 \mathrm{p} K_{\mathrm{a}}$ & 10.7 & 8.3 \\
$\mathrm{H}^{260 A}{ }^{\mathrm{d}}$ & $\mathrm{C} 1, \mathrm{C} 2, \mathrm{C} 3$ & - & - & - \\
$\mathrm{Y}^{263 F}$ & $\mathrm{C} 1$ & $\mathrm{~S}-1 \mathrm{p} K_{\mathrm{a}}$ & 10.6 & - \\
$\mathrm{H} 260 \mathrm{~A} / \mathrm{Y} 263 \mathrm{~F}$ & $\mathrm{C} 1$ & $\mathrm{~S}-1 \mathrm{p} K_{\mathrm{a}}$ & 8.0 & - \\
\hline
\end{tabular}

${ }^{\mathrm{a}} \mathrm{C} 1, \mathrm{C} 2, \mathrm{C} 3$ are the components Comp1, Comp2 and Comp3 used to deconvolute the spectra

${ }^{\mathrm{b}} \mathrm{S}$ and $\mathrm{G}$ refer to the single or global fit respectively of the component(s) in the data set with one or two $\mathrm{p} K_{\mathrm{a}} \mathrm{s}$. For the single fit, $\mathrm{p} K_{\mathrm{a} 1}$ refers to the $\mathrm{p} K_{\mathrm{a}}$ for BV deprotonation. For global fits, the $\mathrm{p} K_{\mathrm{a}}$ values 1 and 3 correspond to those outlined in the model in Figure 5 of the main text. Standard errors from Origin fitting ranged from 0.3 to $4 \%$ of the fitted value. The $\mathrm{p} K_{\mathrm{a}}$ values reported in the table are an average from fits to two separate titrations. The $95 \%$ confidence interval was in general $0.2 \mathrm{pH}$ units except values with asterisks* which had $95 \%$ confidence intervals between 0.4 and 0.6

${ }^{\mathrm{c}}$ For WT and H290T, although $\mathrm{C} 1$ can be individually fit with one $\mathrm{p} K_{\mathrm{a}}$, global fits of $\mathrm{C} 1 \& \mathrm{C} 2$ require at least two $\mathrm{p} K_{\mathrm{a}}$ values. The global fit with $4 \mathrm{p} K_{\mathrm{a}} \mathrm{s}$ is reported in the main text.

${ }^{\mathrm{d}}$ Individual fits of $\mathrm{H} 260 \mathrm{~A}$ components require at least two $\mathrm{p} K_{\mathrm{a}}$ s but do not provide meaningful information. The best fit to the data is with the four $\mathrm{p} K_{\mathrm{a}}$ model reported in the main text. 


\section{SUPPORTING METHODS}

\section{Reversibility Measurements}

$D r$-PSM was added to $30 \mathrm{mM}$ Glycine (pH 10.4 and/or 9.8) and a final concentration of $4 \mu \mathrm{M}$ monomer and then diluted 1:1 into $60 \mathrm{mM}$ Mes buffer ( $\mathrm{pH} 5.5$ to $\mathrm{pH} 6.2$ ) and the absorption spectra was measured. The final $\mathrm{pH}$ of the sample as reported was then measured with a pH meter. Spectra were scaled to an absorbance at $280 \mathrm{~nm}$ of 1 . In order to determine the reversibility, the absorbance spectra of constructs were also measured in $\mathrm{pH} 6.5,7.1$ and 7.5 buffer (i.e. the same conditions determined after dilution from high into low $\mathrm{pH}$ ). The absorbance at $280 \mathrm{~nm}$ and $700 \mathrm{~nm}$ were used to calculate percent reversibility: $100 \times($ absorbance after dilution from high to low $\mathrm{pH}) \div$ (absorbance in low $\mathrm{pH}$ ). Spectral decomposition was also used to compare the shape of the $\mathrm{Q}$ band (450 to $800 \mathrm{~nm}$ ) using SPLAB (6).

\section{UV absorbance}

Absorption spectra were scaled so that the absorption at $320 \mathrm{~nm}$ was set to zero and the value at $280 \mathrm{~nm}$ was set to 1 . The spectrum measured at the lowest $\mathrm{pH}$, which was in the range of $\mathrm{pH} 6.5$ to 7.2 , was then subtracted from the spectra measured at the higher $\mathrm{pH}$ values. These difference spectra are plotted in Figure S8. The averaged $\Delta$ absorbance using values at 300, 301 and $302 \mathrm{~nm}$ as well as the single $\Delta$ absorbance value at $293 \mathrm{~nm}$ were plotted as a function of $\mathrm{pH}$ in Figure $\mathrm{S} 9$. Since the protein spectra have been normalized to an absorbance at $280 \mathrm{~nm}$ of 1 , the apparent protein concentration is then $13.5 \mu \mathrm{M}$ monomer using a theoretically calculated extinction coefficient of $73910 \mathrm{M}^{-1} \mathrm{~cm}^{-1}$ at $280 \mathrm{~nm}$.(7) The protonated tyrosine spectra was obtained using 1 $\mathrm{mL}$ of $0.1 \mathrm{mM}$ solution of L-Tyrosine (Sigma Aldrich) in water. The spectrum did not change after adding $2 \mu \mathrm{L}$ of $1 \mathrm{M} \mathrm{HCL}$. The deprotonated spectra was obtained by adding $6 \mu \mathrm{L}$ of $1 \mathrm{M} \mathrm{NaOH}$. 
The spectrum did not change upon further additions of $\mathrm{NaOH}$. The spectra are normalized to 13.5 $\mu \mathrm{M}$ in Figure $\mathrm{S} 8(\mathrm{~F})$ using an extinction coefficient of the protonated form of $1280 \mathrm{M}^{-1} \mathrm{~cm}^{-1}$ at 280 $\mathrm{nm}$ and a $1 \mathrm{~cm}$ path length cuvette. The difference spectrum was obtained by subtracting the protonated from the deprotonated spectrum. This then corresponds to the absorbance difference of one tyrosine per monomer of $\mathrm{Dr}$-PSM when the protein spectrum is normalized using $280 \mathrm{~nm}$ equal to 1.

\section{Fluorescence Measurements}

Fluorescence emission experiments were carried out using a Cary Eclipse fluorescence spectrophotometer. Excitation wavelength was set to $275 \mathrm{~nm}$ with excitation and emission monochromator band paths set to $2.5 \mathrm{~nm}$. The scan rate was $120 \mathrm{~nm} / \mathrm{min}$ with $1 \mathrm{~nm}$ data intervals and $0.5 \mathrm{~s}$ averaging time. Each scan was repeated five times and then averaged. Measurements were carried out in $30 \mathrm{mM}$ Tris buffer $\mathrm{pH} 7.1$ and 8.9 at $4 \mu \mathrm{M}$ monomer for WT and $\mathrm{Y} 263 \mathrm{~F}$ and 2.2 $\mu \mathrm{M}$ monomer H260A and H260A/Y263F. The absorbance spectra was measured before and after fluorescence which confirmed there was no change in absorbance due to the fluorescence measurement. The UV absorbance region (250 to $320 \mathrm{~nm}$ ) was used to normalize the fluorescence using spectral decomposition with the spectra of WT pH 7.1 as the standard and a first order polynomial baseline to account for slight differences in scattering. The reported multiplication factor (1.01 to 0.97 ) was then used to normalize the fluorescence spectra measured with different constructs and $\mathrm{pH}$ values. Each full absorbance and fluorescence experiment was carried out two times and the resulting spectra averaged. 


\section{Models used for fitting $\mathrm{pH}$ titration data}

The simplest case involves one titration group and can be considered a two-state model between protonated and deprotonated forms:

$$
\boldsymbol{X} H^{+} \stackrel{K_{a}}{\leftrightarrow} \boldsymbol{X}+H^{+}
$$

In equation S1, the protonated and deprotonated forms are shown as $X H^{+}$and $\boldsymbol{X}$ respectively, but, can also be written as $\mathrm{XH}$ and $X^{-}, H^{+}$is the proton which has a positive charge and $K_{\mathrm{a}}$ is the equilibrium constant:

$$
K_{a}=\frac{[X]\left[H^{+}\right]}{\left[X H^{+}\right]}
$$

Equation S2

Equation S2 can be rearranged to give the Henderson Haselbach equation:

$$
p H=p K_{a}+\log \frac{[X]}{\left[X H^{+}\right]}
$$

Using Equation S3, the fraction of the protonated and deprotonated groups at a given $\mathrm{pH}$ are

$$
\begin{gathered}
f X H^{+}=\frac{X H^{+}}{\boldsymbol{X}+\boldsymbol{X} H^{+}}=\frac{1}{10^{(p H-p K a)+1}} \\
f \boldsymbol{X}=\frac{X}{\boldsymbol{X}+\boldsymbol{X} H^{+}}=\frac{1}{1+10^{\left(p K_{a}-p H\right)}}
\end{gathered}
$$

The total signal (determined by absorbance or by component analysis) is the sum of the fraction of each species in solution multiplied by their individual signals.

$$
S=S_{a}\left(f X H^{+}\right)+S_{b}(f X)
$$

Where $S$ is the signal determined at a given $\mathrm{pH}, S_{a} / S_{b}$ is the signal associated with $X H^{+} / X$ which corresponds to the value at the low/high $\mathrm{pH}$ titration endpoint.

Since the sum of the fraction of all species in solution is equal to 1, Equation S5 can be cast using the total change in absorbance or component contribution during titration given, $\Delta S=S_{a}-$ $S_{b}:$ 


$$
S=S_{b}+\Delta S \frac{1}{10^{(p H-p K a)}+1}
$$

Deviation from this fit may indicate the presence of more than one titration group. Fitting to the Hill equation below can give an unbiased assessment of the applicability of fitting to a more complex model.

$$
S=S_{b}+\Delta S \frac{\left(10^{-p H}\right)^{n}}{\left(10^{-M P}\right)^{n}+\left(10^{-p H}\right)^{n}}
$$

Where $n$ is the Hill coefficient (a value of 1 indicates a single species is being titrated and values above or below indicate that more than one $\mathrm{pH}$ dependent process is taking place), $M P$ is the midpoint in $\mathrm{pH}$ units of the $\mathrm{pH}$ titration, which, when the Hill coefficient is 1 , is equal to the $\mathrm{p} K_{\mathrm{a}}$.

For a three-state model that involves two titration groups, the following equation can be used for fitting:

$$
S=\frac{\Delta S_{1}}{1+10^{\left(p K_{a 1}-p H\right)}}+\frac{\Delta S_{2}}{1+10^{\left(p K_{a 2}-p H\right)}}+S_{a}
$$

In Equation $\mathrm{S} 7$, the two $\mathrm{p} K_{\mathrm{a}}$ values, $\mathrm{p} K_{\mathrm{a} 1}$ and $\mathrm{p} K_{\mathrm{a} 2}$, with corresponding amplitude changes $\Delta S_{1}$ and $\Delta S_{2}$ are assumed to be from two completely independent titrations.(8)

For phytochrome, titration groups can be from BV, nearby amino acids that influence BV absorbance, or, a combination of the two. If the two titration groups are considered to be from the same phytochrome monomer subunit, the following thermodynamic cycle can be drawn:

$$
\begin{array}{ccc}
\boldsymbol{X} H \boldsymbol{Y} H^{+} \stackrel{K_{a 1}}{\leftrightarrow} \boldsymbol{X Y} H+H^{+} & \\
K_{a 3} \uparrow & \uparrow K_{a 4} & \text { Equation S8 } \\
\boldsymbol{X} H \boldsymbol{Y}+H^{+} \stackrel{K_{a 2}}{\leftrightarrow} X \boldsymbol{Y}^{-}+2 H^{+} &
\end{array}
$$

Where $X$ and $Y$ are the two titration groups. If $K_{\mathrm{a} 3}<<K_{\mathrm{a} 1}$ and $K_{\mathrm{a} 4}$, the deprotonation events are sequential such that $X$ deprotonates before $Y$. In this case the equation simplifies to: 


$$
\boldsymbol{X} H \boldsymbol{Y} H^{+} \stackrel{K_{a 1}}{\leftrightarrow} \boldsymbol{X Y} H+H^{+} \stackrel{K_{a 4}}{\leftrightarrow} \boldsymbol{X} \boldsymbol{Y}^{-}+2 H^{+}
$$

Using Equations 2 and 3:

$$
p H=p K_{a 1}+\log \frac{[\mathrm{XYH}]}{\left[\mathrm{XHYH}^{+}\right]}=p K_{a 4}+\log \frac{\left[\mathrm{XY}^{-}\right]}{[\mathrm{XY}]} \quad \text { Equation } \mathrm{S} 10
$$

The fraction $f$ of each species is equal to:

$$
f \boldsymbol{X} H \boldsymbol{Y} H^{+}+f \boldsymbol{X Y} H+f \boldsymbol{X} \boldsymbol{Y}^{-}=1 \quad \text { Equation S11 }
$$

From equations 10 and 11

$$
\begin{gathered}
f X \boldsymbol{X} H=\frac{1}{\frac{1}{10^{\left(p H-p K_{a 1}\right)}+10^{\left(p H-p K_{a 4}\right)+1}}} \\
f \boldsymbol{X} H \boldsymbol{Y} H^{+}=\frac{f X Y H}{10^{\left(p H-p K_{a 1}\right)}} \\
f \boldsymbol{X} \boldsymbol{Y}^{-}=\frac{f X Y H}{10^{\left(p H-p K_{a 4}\right)}}
\end{gathered}
$$

From the fraction of each species in Equations 12a-c, the total signal can then be written as in Equation S5 using $S$, the signal associated with each species and an additional scaling factor, $F$.

$$
S=F_{X H Y H^{+}}\left[S_{X H Y H^{+}}\left(f X H Y H^{+}\right)\right]+F_{X Y H}\left[S_{X Y H}(f X Y H)\right]+F_{X Y^{-}}\left[S_{X Y^{-}}\left(f X \boldsymbol{Y}^{-}\right)\right]
$$

Equation S13

The scaling factors $F_{X{ }_{X Y H}+}, F_{X Y H}$ and $F_{X Y^{-}}$are needed when globally fitting multiple data sets as they set how much each species contributes to the signal being fit. For example when globally fitting three components, the $\mathrm{p} K_{\mathrm{a}}$ and $S$ values are shared across all data sets while each component is fit with one scaling factor set to 1 and the other two to 0 .

If the two titration groups in Equation S8 deprotonate in parallel, then $K_{\mathrm{a} 1}+K_{\mathrm{a} 4}=K_{\mathrm{a} 2}+K_{\mathrm{a} 3}$, and the fraction $f$ of each species is equal to:

$$
f \boldsymbol{X} H \boldsymbol{Y} H^{+}+f \boldsymbol{X Y} H+f \boldsymbol{X} H \boldsymbol{Y}+f \boldsymbol{X} \boldsymbol{Y}^{-}=1
$$

From Equations S2, S3 and S11: 


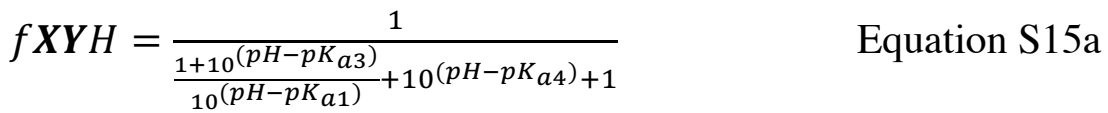

$$
\begin{aligned}
& f \boldsymbol{X} H \boldsymbol{Y} H^{+}=\frac{f X Y H}{10^{\left(p H-p K_{a 1}\right)}} \quad \text { Equation } \mathrm{S} 15 \mathrm{~b} \\
& f \boldsymbol{X} H \boldsymbol{Y}=f \boldsymbol{X} H \boldsymbol{Y} H^{+} \times 10^{\left(p H-p K_{a 3}\right)} \quad \text { Equation } \mathrm{S} 15 \mathrm{c} \\
& f \boldsymbol{X} \boldsymbol{Y}^{-}=f \boldsymbol{X Y H} \times 10^{\left(p H-p K_{a 4}\right)} \quad \text { Equation } \mathrm{S} 15 \mathrm{~d}
\end{aligned}
$$

Using Equations S15a-d, the total signal can be written as described for Equation S13:

$$
S=F_{\boldsymbol{X} H \boldsymbol{Y} H^{+}}\left[S_{\boldsymbol{X} H \boldsymbol{Y} H^{+}}\left(f \boldsymbol{X} H \boldsymbol{Y} H^{+}\right)\right]+F_{\boldsymbol{X Y} H}\left[S_{\boldsymbol{X Y} H}(f \boldsymbol{X Y} H)\right]+F_{\boldsymbol{X} H \boldsymbol{Y}}\left[S_{\boldsymbol{X} H \boldsymbol{Y}}(f \boldsymbol{X H Y})\right]+
$$

$F_{X Y^{-}}\left[S_{X Y^{-}}\left(f X Y^{-}\right)\right] \quad$ Equation S16

\section{REFERENCES}

1. Hirose, Y., N. C. Rockwell, K. Nishiyama, R. Narikawa, Y. Ukaji, K. Inomata, J. C. Lagarias and M. Ikeuchi. (2013) Green/red cyanobacteriochromes regulate complementary chromatic acclimation via a protochromic photocycle. Proc. Natl. Acad. Sci. U. S. A. 110, 4974-4979.

2. Lenngren, N., P. Edlund, H. Takala, B. Stucki-Buchli, J. Rumfeldt, I. Peshev, H. Hakkanen, S. Westenhoff and J. A. Ihalainen. (2018) Coordination of the biliverdin D-ring in bacteriophytochromes. Phys. Chem. Chem. Phys. 20, 18216-18225. 
3. Melo, E. P., M. R. Aires-Barros, S. M. Costa and J. M. Cabral. (1997) Thermal unfolding of proteins at high pH range studied by UV absorbance. J. Biochem. Biophys. Methods 34, 45-59.

4. Grimsley, G. R., J. M. Scholtz and C. N. Pace. (2009) A summary of the measured pK values of the ionizable groups in folded proteins. Protein Sci. 18, 247-251.

5. Maeno, A., H. Matsuo and K. Akasaka. (2013) Tyrosine/tyrosinate fluorescence at $700 \mathrm{MPa}$ A pressure unfolding study of chicken ovomucoid at pH 12. Biophys. Chem. 183, 57-63.

6. Davydov, D. R., E. Deprez, G. H. Hoa, T. V. Knyushko, G. P. Kuznetsova, Y. M. Koen and A. I. Archakov. (1995) High-pressure-induced transitions in microsomal cytochrome P450 2B4 in solution: Evidence for conformational inhomogeneity in the oligomers. Arch. Biochem. Biophys. 320, 330-344.

7. Wilkins, M. R., E. Gasteiger, A. Bairoch, J. C. Sanchez, K. L. Williams, R. D. Appel and D. F. Hochstrasser. (1999) Protein identification and analysis tools in the ExPASy server. Methods Mol. Biol. 112, 531-552.

8. Nielsen, J. E. (2009) Chapter 9 Analyzing Enzymatic pH Activity Profiles and Protein Titration Curves using Structure-Based pKa Calculations and Titration Curve Fitting, in pp 233258, Elesvier Inc, . 